Citation: D. Seress, G. M. Kovács, O. Molnár, M. Z. Németh (2021) Infection of papaya (Carica papaya) by four powdery mildew fungi. Phytopathologia Mediterranea 60(1): 37-49. doi: 10.14601/Phyto-11976

Accepted: September 21, 2020

Published: May 15, 2021

Copyright: () 2021 D. Seress, G. M. Kovács, O. Molnár, M. Z. Németh. This is an open access, peer-reviewed article published by Firenze University Press (http://www.fupress.com/pm) and distributed under the terms of the Creative Commons Attribution License, which permits unrestricted use, distribution, and reproduction in any medium, provided the original author and source are credited.

Data Availability Statement: All relevant data are within the paper and its Supporting Information files.

Competing Interests: The Author(s) declare(s) no conflict of interest.

Editor: Thomas A. Evans, University of Delaware, Newark, DE, United States.

\section{Research Papers \\ Infection of papaya (Carica papaya) by four powdery mildew fungi}

\author{
Diána SERESS ${ }^{1}$, Gábor M. KOVÁCS ${ }^{1,2}$, Orsolya MOLNÁR ${ }^{1}$, Márk Z. \\ NÉMETH ${ }^{1, *}$ \\ ${ }^{1}$ Plant Protection Institute, Centre for Agricultural Research, Eötvös Loránd Research \\ Network (ELKH), 1525 Budapest, P.O. Box 102, Hungary \\ ${ }^{2}$ Eötvös Loránd University, Institute of Biology, Department of Plant Anatomy, Budapest, \\ Hungary \\ *Corresponding author. E-mail: nemeth.mark@atk.hu
}

\begin{abstract}
Summary. Papaya (Carica papaya L.) is an important fruit crop in many tropical and subtropical countries. Powdery mildew commonly affects this host, causing premature leaf loss, reduced yields and poor fruit quality. At least fifteen different fungi have been identified as the causal agents of papaya powdery mildew. Powdery mildew symptoms were detected on potted papaya plants growing in two locations in Hungary. This study aimed to identify the causal agents. Morphology of powdery mildew samples was examined, and sequences of two loci were used for molecular taxonomic identifications. Only anamophs were detected in all samples, and four morphological types were distinguished. Most samples had Pseudoidium anamorphs, while some were of the Fibroidium anamorph. Based on morphology and molecular taxonomy, the Fibroidium anamorph was identified as Podosphaera xanthii. The Pseudoidium anamorphs corresponded to three different Erysiphe species: E. cruciferarum, E. necator and an unidentified Erysiphe sp., for which molecular phylogenetic analyses showed it belonged to an unresolved species complex of E. malvae, E. heraclei and E. betae. Infectivity of P. xanthii and E. necator on papaya was verified with cross inoculations. A review of previous records of powdery mildew fungi infecting papaya is also provided. Podosphaera xanthii was known to infect, and E. cruciferarum was suspected to infect Carica papaya, while E. necator was recorded on this host only once previously. No powdery mildew fungus belonging to the E. malvae/E. heraclei/E. betae species complex is known to infect papaya or any other plants in the Caricaceae, so the unidentified Erysiphe sp. is a new record on papaya and the Caricaceae. This study indicates host range expansion of this powdery mildew fungus onto papaya.
\end{abstract}

Keywords. Carica, Erysiphales, Erysiphe necator, host range expansion, phylogenetic analysis, Pseudoidium.

\section{INTRODUCTION}

Papaya (Carica papaya L.) is a tree native to Central America (Carvalho, 2013) that is cultivated for its fruit in many tropical and subtropical countries. In Europe, Spain is the largest papaya producer, with plants grown on 
the Canary Islands and the southern regions of mainland Spain (Honoré et al., 2020). The most economically important papaya products are edible fruits and the papain enzyme extracted from the fruits (Carvalho, 2013; Carvalho et al., 2015). Papain is widely used in beer production, medicines, as a meat tenderizer and for softening textiles and leather (Carvalho, 2013). Additionally, papaya trees are planted for their ornamental value.

Papaya is very susceptible to several diseases (Rawal, 2010). Most of these, such as root and foot rot, damping off, different types of leaf spots, powdery mildew, anthracnose and stem end rot, are caused by fungi or oomycetous pathogens (Ventura et al., 2004; Rawal, 2010). Among these, anthracnose and other postharvest diseases are considered the most important, but the significance of these diseases varies with the growing region (Ventura et al., 2004). Powdery mildew on papaya is generally regarded as a disease of minor importance, but it has been reported to be severe in some regions (Liberato et al., 2004; Ventura et al., 2004; Rawal, 2010; Cunningham and Nelson, 2012). Powdery mildew on papaya causes premature leaf drop, reduced yields, poor fruit quality (Cunningham and Nelson, 2012), and may also kill seedlings (Ventura et al., 2004). Identification of the causal species of powdery mildews is complicated because the vegetative stages of these fungi are often morphologically similar or indistinguishable (Braun et al., 2017).

Braun et al. (2017) settled some taxonomic questions concerning powdery mildew fungi infecting papaya, described two new species, and provided a key for identification of the pathogens. At least four Erysiphe species commonly occur on papaya (Braun et al., 2017). Erysiphe caricae was described from Switzerland after it was detected on greenhouse-grown plants of babaco (mountain papaya, Vasconcellea $\times$ heilbornii) (Bolay, 2005). Other Erysiphe species infecting papaya include E. caricae-papayae (in Thailand and Taiwan), which is newly described, E. diffusa (in Brazil, Taiwan and possibly several other countries) and E. fallax, also newly described (in the United States of America and Mexico) (Braun et al., 2017). In addition, E. necator was detected from a sample originating from Hawaii, which was attributed to "accidental infection" (Braun et al., 2017). Two Podosphaera species were reported on papaya, $P$. caricicola (in Thailand, Taiwan, in the United States of America, and probably also in Australia and Java) (Braun et al., 2017), and P. xanthii (in Taiwan and Korea) (Tsay et al., 2011; Joa et al., 2013). Four Phyllactinia species are also known to occur on papaya, including $\mathrm{Ph}$. caricae, $\mathrm{Ph}$. caricicola, $\mathrm{Ph}$. papayae and Ph. caricifolia (Takamatsu et al., 2016). Tsay et al. (2011) listed three powdery mildew fungi responsible for the disease on papaya. In addition to E. diffusa and P. xanthii, Pseudoidium neolycopersici, the pathogen associated with tomato powdery mildew (Kiss et al., 2001) was found to be widespread in papaya plantations in Taiwan (Tsay et al., 2011). Pseudoidium neolycopersici was also reported from China, and its identification was verified with cross inoculations onto tomato (Mukhtar and van Peer, 2018). Other species, such as E. cruciferarum, P. macularis, Golovinomyces orontii and Leveillula sp. are also listed as powdery mildew fungi infecting papaya, although the status of these species on papaya is lesser known, or the identifications are doubtful (Liberato et al., 2004; Braun et al., 2017). Altogether, about fifteen different powdery mildew species (including insufficiently known taxa) are thought to infect papaya, based on the data currently available (Table 1). In Europe, Erysiphe diffusa was recently reported from papaya plants in Spain (Vielba-Fernández et al., 2019), the main papaya producing country on that continent. Three other powdery mildew fungi, Oidium papayae (now thought to represent E. diffusa) (Liberato et al., 2004; Braun et al., 2017), Sphaerotheca caricae-papayae (now P. xanthii) (Braun et al., 2017), and Leveillula taurica, were reported from Portugal (Sequeira, 1992). Additional reports from Europe include samples identified as E. caricae from Switzerland (Bolay, 2005), Ukraine (Takamatsu et al., 2015) and Germany (Braun et al., 2017).

We have detected powdery mildew symptoms on papaya plants at two locations in Hungary. The aim of the present study was to characterize and identify the causal agents of powdery mildew on the infected plants.

\section{MATERIALS AND METHODS}

\section{Samples and morphology}

In 2018 and 2019, spontaneous powdery mildew infections were observed on young papaya plants growing in pots as hobby plants in a family yard in Győrújbarát, and in a greenhouse, on plants intended for research purposes in Budapest, Hungary. All these plants were grown from germinated seeds originating from one fruit.

Samples collected during this study are listed in Supplementary Table 1. Fresh powdery mildew colonies were sampled with cellotape and mounted in glycerine on microscope slides. Samples were also prepared using the lactic acid boiling method (Shin and La, 1993). For morphological characterization, a Zeiss Axioskop 2 Plus microscope was used with an AxioCam ICc5 camera. Size, shape and development of conidia (singly or in 


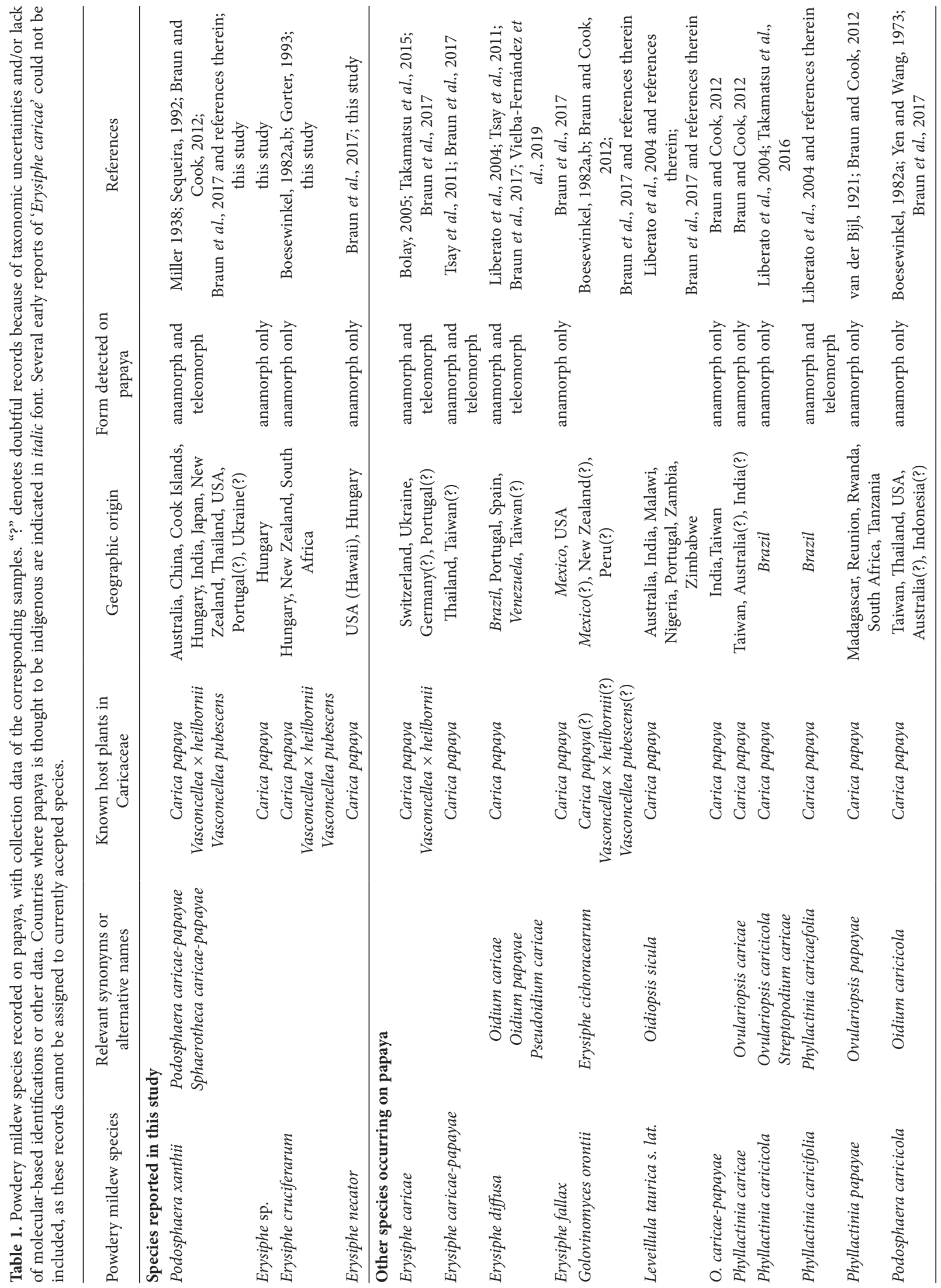


chains), presence of fibrosin bodies in conidia, lengths of conidiophores, size of foot-cells, and morphology of hyphal appressoria were determined. Thirty conidia and all available conidiophores, including foot-cells, were measured from each sample. Type of conidium germination was noted when observed.

Representative herbarium specimens from each morphological type were deposited at the Mycological Collection of the Hungarian Natural History Museum, under accession numbers HNHM-MYC-008079 (111134BP) to HNHM-MYC-008083 (111138BP).

\section{Sequence determinations}

Genomic DNA was extracted from powdery mildew material removed from leaf surfaces with cellotape, using the sample boiling method (Pintye et al., 2020), or from powdery mildew-infected leaf fragments using the DNeasy Plant Mini Kit (Qiagen), following the manufacturer's instructions. The internal transcribed spacer (ITS) region of the nuclear ribosomal DNA (nrDNA) was amplified in two fragments (Scholler et al., 2016) using the primer pairs ITS5-PM6 and PM5-ITS4 (Takamatsu and Kano, 2001). A fragment of Minichromosome Maintenance Complex Component 7 encoding gene $(\mathrm{Mcm} 7)$ was amplified with primers Mcm7F2 and Mcm7R8 (Ellingham et al., 2019). For amplifications, Phusion Green Hot Start II High-Fidelity PCR Master Mix (Thermo Fisher Scientific) was used as recommended by the manufacturer, with primer annealing temperatures set to $58^{\circ} \mathrm{C}$ for ITS and $55^{\circ} \mathrm{C}$ for $\mathrm{Mcm} 7$ amplifications. The reaction mixture contained $1 \mu \mathrm{L}$ of template DNA in the ITS and $2 \mu \mathrm{L}$ in the $M c m 7$ amplifications. Amplicons were run on $1 \%$ agarose gel, and were sent for sequencing to LGC Genomics GmbH. Sequencing was done with the same primers used for the amplifications. The resulting chromatograms were processed with Staden Program Package (Staden et al., 2000) and CodonCode Aligner version 9.0.1 (CodonCode Corporation). Sequences determined in this study were deposited in GenBank under accession numbers MT658714 to MT658729 and MT755388 to MT755394 (Supplementary Table 1).

\section{Sequence analyses}

Three phylogenetic analyses were conducted using ITS sequences (as in Braun et al., 2017): one with sequences of samples belonging to the Microsphaera lineage of Erysiphe (Takamatsu et al., 2015), the second with E. necator sequences, and the third with sequences of Podosphaera xanthii and closely relat- ed species. These analyses used the determined ITS sequences and sequences from the datasets of Braun et al. (2017), supplemented with additional sequences from closely related species obtained from GenBank after a search with Basic Local Alignment Search Tool (BLAST; Altschul et al., 1990). The E. necator dataset also contained ITS sequences of isolates originating from non-Vitaceae hosts (Fonseca et al., 2019; Pieroni et al., 2020).

ITS alignments were prepared using MAFFT online (Katoh and Standley, 2013) with the E-INS-i algorithm (other settings were used as defaults). Leading and trailing gaps were included as unknown characters.

$\mathrm{Mcm} 7$ sequences from fungi of morphological types 2, 3 and 4 determined in this study were aligned with sequences from other Erysiphe sp. samples (Ellingham et al., 2019; Shirouzu et al., 2020) with FFT-NS-i algorithm of MAFFT online, and were added to the ITS dataset of the same samples, creating a combined ITS $M c m 7$ alignment.

Two Cystotheca species, E. ornata and E. necator var. ampelopsidis, were used as outgroups in the ITS analyses based on the results of Braun et al. (2017). For the ITS Mcm7 dataset, Arthrocladiella mougeotii and Golovinomyces bolayi were used as outgroup (Shirouzu et al., 2020).

Phylogenetic analyses were carried out with the maximum likelihood (ML) method using raxmlGUI 1.5 (Silvestro and Michalak, 2012; Stamatakis, 2014). For the analysis of the ITS_Mcm7 dataset, two partitions were set according to the two loci. Branch supports were calculated from 1000 bootstrap replicates. Phylogenetic trees resulting from analyses were visualized in TreeGraph 2.14.0 (Stöver and Müller, 2010) and were submitted to TreeBASE (study ID 26269).

\section{Cross inoculation experiments}

Cross inoculations were conducted with $P$. xanthii and E. necator. The two other powdery mildew fungi detected on papaya were not used.

Papaya plants (both infected and healthy) used in these experiments were less than 1 year old, and were $30-50 \mathrm{~cm}$ in size. These plants were germinated from the same batch of seeds as the plants originally identified as powdery mildew infected. The seeds were collected from a commercially available papaya fruit of unknown variety, originating from Indonesia. Other plant species used in cross inoculation tests were 1-month-old cucumber plants (Cucumis sativus 'Párizsi Fürtös') and 8-monthold grapevine (Vitis vinifera 'Chardonnay') plants grown from cuttings in pots. 
Table 2. Summary of cross inoculation test results. (+) denotes successful infections and (-) denotes no infection.

\begin{tabular}{|c|c|c|c|c|}
\hline Inoculum & $\begin{array}{c}\text { To } \\
\text { papaya c }\end{array}$ & $\begin{array}{c}\text { To } \\
\text { cucumber }\end{array}$ & $\begin{array}{c}\text { To } \\
\text { grapevine }\end{array}$ & $\begin{array}{c}\text { To in vitro } \\
\text { grapevine } \\
\text { leaves }\end{array}$ \\
\hline $\begin{array}{l}\text { Podosphaera xanthii ex } \\
\text { papaya }\end{array}$ & - & + & & \\
\hline $\begin{array}{l}\text { Podosphaera xanthii ex } \\
\text { cucumber }\end{array}$ & + & + & & \\
\hline Erysiphe necator ex papaya & - & & - & + \\
\hline $\begin{array}{l}\text { Erysiphe necator ex } \\
\text { grapevine }\end{array}$ & + & & + & + \\
\hline
\end{tabular}

The first series of experiments were carried out with powdery mildew from $P$. xanthii-infected papaya and cucumber plants onto healthy papaya and cucumber plants, by gently pressing the diseased leaves onto the surfaces of healthy leaves. In the second set of experiments E. necator-infected papaya and grapevine plants were used on to similarly inoculate healthy papaya and grapevine plants. All inoculations included two seedlings of each tested plant species to be inoculated, and two plants as positive controls, with the respective powdery mildew-inoculated to the same host plant species. Inoculated seedlings were covered with powdery mildew impermeable transparent plastic foil. Two uninoculated plants from each species were used as negative controls. All experiments were conducted twice.

In addition, transfer of E. necator from papaya and grapevine onto grapevine leaves maintained in an in vitro system was tested. In vitro grapevine plantlets were micropropagated from two-nodal explants grown on Murashige and Skoog (MS) medium (Murashige and Skoog, medium Mod. No. 1B, Duchefa) solidified with $6.5 \mathrm{~g} \mathrm{~L}^{-1}$ phyto agar (Murashige and Skoog, 1962; Aziz et al., 2003). Plants were grown at $22^{\circ} \mathrm{C}$ with a daily $12 \mathrm{~h}$ photoperiod. Grapevine leaves were cut under sterile conditions and cultivated further on the same medium in disposable Petri dishes. Conidia from powdery mildew on papaya were placed on grape leaves using a sterile glass needle under sterile conditions. The Petri dishes were then incubated under the same conditions as the in vitro grapevine plantlets.

Inoculated plants and in vitro leaves were checked regularly for symptom development. When powdery mildew colonies were observed, the identity of the fungus was verified with microscopic analysis as described above. Cross inoculation experiments are summarized in Table 2.

\section{RESULTS}

Small powdery spots, each a few $\mathrm{cm}^{2}$ in size, were detected on the stems and/or adaxial surfaces of the leaves on all plants investigated (Figure 1). No infection was detected on abaxial leaf surfaces. Some of the infected leaves became necrotic and curled, and later dried and fell off the plants.

According to morphological analysis by light microscopy, infections on some leaves were caused by powdery mildew fungi belonging to the Fibroidium, while others belonged to the Pseudoidium anamorphs. Four morphological types of powdery mildew fungi occurred in our samples, one Fibroidium morphological type and three Pseudoidium anamorphs with slightly differing morphology (Figure 2). Chasmothecia were not detected in any sample.

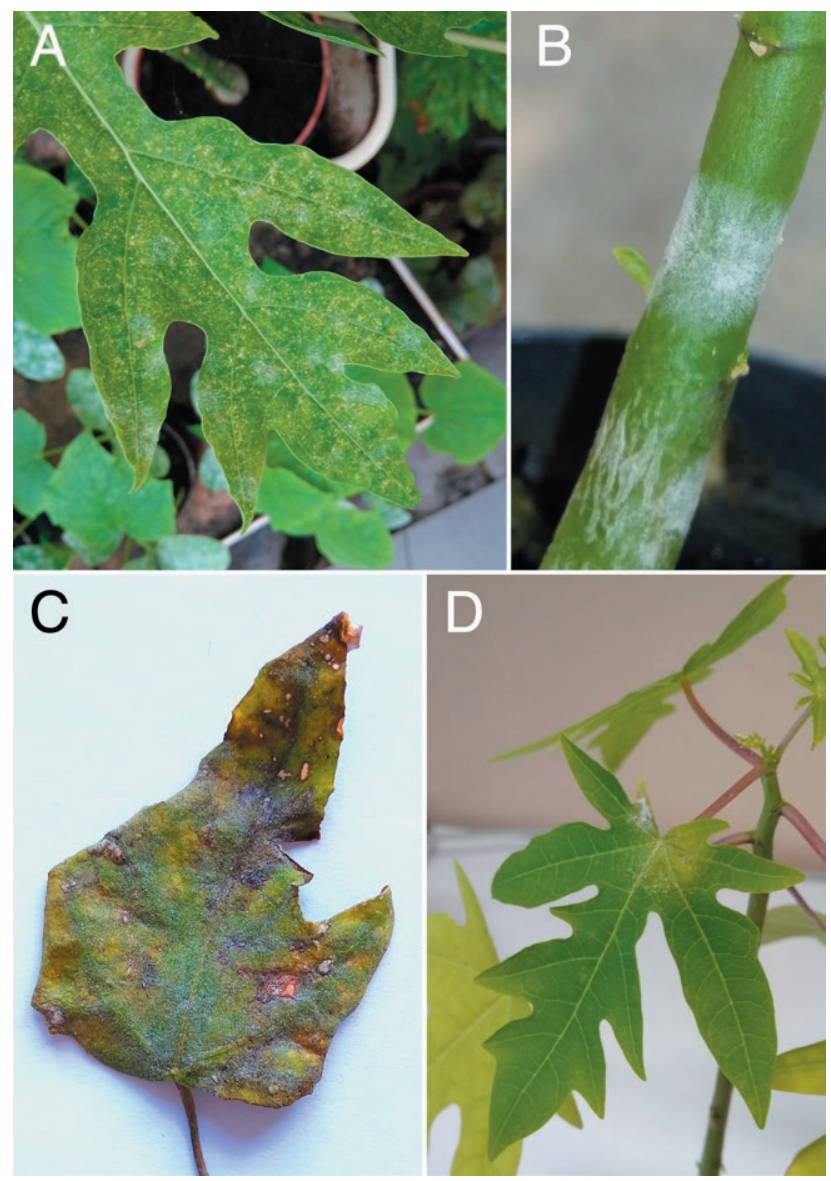

Figure 1. Powdery mildew symptoms on papaya plants. Symptoms caused by: A) Podosphaera xanthii, B) Erysiphe sp., C) Erysiphe cruciferarum and D) Erysiphe necator. 


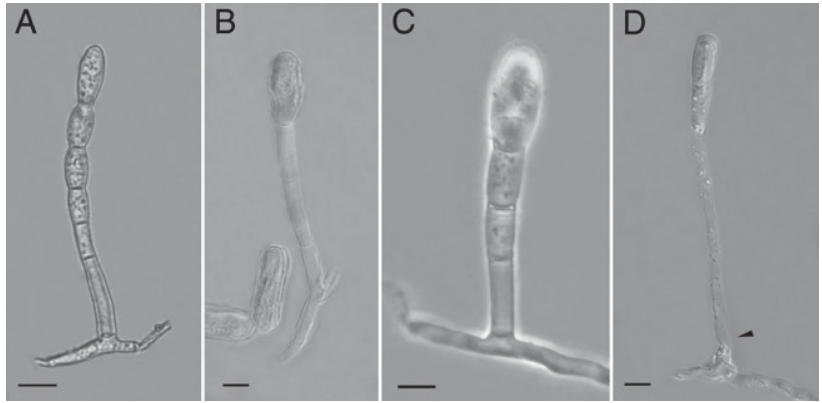

Figure 2. Conidiophore morphology of the four different powdery mildew morphological types designated in this study. A) Podosphaera xanthii, B) Erysiphe sp., C) E. cruciferarum, D) E. necator. Arrow in D) indicates the twisted conidiophore foot cell, characteristic of E. necator. Bars $=20 \mu \mathrm{m}$.

\section{Morphological types}

Morphological type 1. This type was detected in samples collected only in Budapest (Supplementary Table 1). Infections in most cases caused small, but well visible colonies on adaxial leaf surfaces. The fungus had Fibroidium anamorph, characterized by indistinct hyphal appressoria and production of conidia in chains. Conidium chains usually contained four to six conidia. Conidiophores measured up to $356 \mu \mathrm{m}$ (including conidium chains), averaging $215 \mu \mathrm{m}$. Conidiophore foot cells were $57-94 \mu \mathrm{m} \times 8-13 \mu \mathrm{m}$ and were each usually surmounted by $2-3$ shorter cells. Foot cells sometimes showed slight constrictions at the basal septae. Conidia were doliiform, 25-40 $\mu \mathrm{m}$ in length, and 13-25 $\mu \mathrm{m}$ in width and contained fibrosin bodies, which were visible when mounting without boiling. Conidium germination was lateral and germ tubes did not have distinct appressoria. Based on morphological characteristics, the fungi in these samples were tentatively identified as Podosphaera xanthii.

Morphological types 2, 3 and 4 were identified as Erysiphe spp. based on morphology similar to Pseudoidium anamorphs (Braun and Cook, 2012).

Morphological type 2. A morphologically different subset of samples collected in Budapest (Supplementary Table 1) had small, distinct colonies, mainly on stems and petioles of affected host plants. Hyphae formed lobed appressoria. Conidiophores measured 97-152 $\mu \mathrm{m}$, their foot cells were $26-47 \mu \mathrm{m} \times 9-12 \mu \mathrm{m}$, and these were each surmounted by two shorter cells. Conidia formed singly, were cylindrical or doliiform with lengths of $35-50 \mu \mathrm{m}$ and widths of $13-23 \mu \mathrm{m}$, and lacked fibrosin bodies. Conidia germinated terminally with short germ tubes which formed lobed to multilobed appressoria.
Morphological type 3. A proportion of samples collected in Budapest and Györújbarát (Supplementary Table 1) was characterized by thin, evanescent to persistent colonies on petioles and on adaxial leaf surfaces of affected hosts. These fungi developed lobed hyphal appressoria. Conidiophores measured 70-121 $\mu \mathrm{m}$. Conidiophore foot cells were $18-33 \mu \mathrm{m} \times 7-12 \mu \mathrm{m}$, and were each surmounted by two shorter cells. Conidiophores each produced single cylindrical conidia, with lengths of $28-45 \mu \mathrm{m}$ and widths of $10-20 \mu \mathrm{m}$, without fibrosin bodies. Conidia germinated terminally and formed moderately lobed appressoria.

Morphological type 4. Powdery mildew of other samples from papaya in Budapest and in Győrújbarát (Supplementary Table 1) developed thin or persistent colonies on host plants. Hyphal appressoria were lobed to multilobed. Conidiophores were highly variable in length, from $109 \mu \mathrm{m}$ to sometimes slightly longer than $300 \mu \mathrm{m}$, averaging $205 \mu \mathrm{m}$. Conidiophore foot cells measured $73-154 \mu \mathrm{m} \times 5 \mu \mathrm{m}$. A portion of foot cells was sinuous or spirally twisted. Foot cells were usually surmounted by two shorter cells. Conidia formed singly, and were ellipsoid-ovoid or doliiform, 30-45 $\mu \mathrm{m}$ long and 15-20 $\mu \mathrm{m}$ wide, and did not contain fibrosin bodies. Conidia germinated terminally and formed lobed appressoria, or germination followed longitubus pattern. Based on these characteristics (Nomura et al., 2003; Braun and Cook, 2012), the fungus was tentatively identified as E. necator.

\section{Sequence analyses}

Molecular taxonomic analyses of the nrDNA ITS region were carried out for 16 samples, representing all four morphological types. The dataset for the phylogenetic analysis of Podosphaera species included 46 sequences (including two newly determined sequences) and had a length of 480 characters, while the dataset with Erysiphe species in the Microsphaera lineage contained 85 sequences (including six newly sequenced) and the alignment consisted of 530 characters. The alignment of Erysiphe necator ITS sequences contained 27 sequences (of which eight were determined in the present study) and had 529 characters. The combined dataset of ITS and $M c m 7$ sequences contained newly obtained sequences from seven samples, and altogether 62 samples, with an alignment length of 1068 characters, from which the $M c m 7$ partition had 468 characters.

The identical ITS sequences determined from two Hungarian samples representing the $P$. xanthii morphotype formed a clade with three other identical $P$. xanthii sequences from powdery mildews originating from 
Cucumis, Helianthus and Saintpaulia (Supplementary Figure 1).

In the phylogenetic analysis of the Microsphaera lineage of Erysiphe species, ITS sequences from the various samples from papaya were spread across six different clades (Figure 3). The Hungarian isolates (morphological types 2 and 3 ) were found in two of the clades. The three samples belonging to morphological type 2 had identical ITS sequences. These clustered in a clade containing identical sequences of other powdery mildew fungi identified as E. malvae, E. heraclei and E. betae, infecting five different plant species. ITS of two other samples labelled as E. heraclei and E. betae differed in one nucleotide position from the former samples (Figure 3). Three sequences from samples of morphological type 3 clustered in a clade formed by sequences of powdery mildews infecting Brassicaceae hosts (Figure 3). The ITS sequences of powdery mildew fungi from our papaya samples from Budapest and Győrújbarát, and Brassica sp., Raphanus sativus and Sisymbrium officinale, were identical.

In the combined ITS_Mcm7 analysis, samples from morphological type 2 similarly clustered together in a well supported clade with samples labelled as E. malvae, $E$. heraclei and E. betae (Figure 4). However, sequences of our samples differed at least in one nucleotide position from all currently known $M c m 7$ sequences.

The phylogenetic analysis of E. necator ITS sequences resulted in two groups, and both groups contained samples from papaya as well as from grapevine (Figure 5). Three of our papaya samples collected in Györújbarát with identical ITS sequences formed a group with eight other identical sequences of powdey mildews from Vitis sp. and one from Caryocar brasiliense, and two other sequences differing in one position from the Hungarian samples. ITS sequences of E. necator infecting cashew differed in three nucleotides, while the ITS of the isolate infecting rubber tree differed in two nucleotides from our sequences belonging to this group.

Five of our papaya samples with identical sequences from Budapest formed a clade with three E. necator samples, including one originating from papaya, and two others from $V$. vinifera (Figure 5). These were all characterized by the same nucleotide sequence. In addition, an Australian E. necator sample from grapevine differed in one nucleotide from these sequences.

\section{Cross inoculation tests}

Results of cross inoculation tests are summarized in Table 2. Cross inoculations from infected papaya plants to healthy papaya plants were unsuccessful in experi- ments involving P. xanthii. However, healthy cucumber plants, regular hosts of $P$. xanthii, could be infected with the powdery mildew originating from papaya. Cucumber plants developed powdery mildew symptoms after $11 \mathrm{~d}$.

Visible powdery mildew patches developed on the inoculated papaya leaves $11 \mathrm{~d}$ after inoculations with $P$. xanthii from cucumber, indicating that infection with powdery mildew from cucumber to papaya was successful (Supplementary Figure 2A). The same inoculum also infected healthy cucumber plants inoculated as controls.

Symptomless papaya plants and grapevine plants became infected with $E$. necator from grapevine, but not with E. necator from papaya. However, an E. necator sample from papaya (PM198) and another E. necator sample from grapevine as a control, were successfully used for starting in vitro powdery mildew cultures on $V$. vinifera leaves, causing symptoms 10-12 d after inoculations (Supplementary Figure 2B). The powdery mildews have been maintained on in vitro grapevine leaves.

\section{DISCUSSION}

Carica papaya and other Carica species are hosts of numerous powdery mildew species representing many different lineages of Erysiphales (Table 1). Based on morphological and sequence analyses, we detected Podosphaera xanthii and three Erysiphe spp. occurring on papaya plants in Budapest and Györújbarát, Hungary.

Podosphaera xanthii, generally known as cause of powdery mildew on cucurbits, has a broad host range (Pérez-García et al., 2009; Braun and Cook, 2012) which is expanding as new hosts are reported (eg. Fan et al., 2019; Nayak and Babu, 2019; Nemes et al., 2019). Previous cross inoculation studies (Miller, 1938; Alcorn, 1968; Munjal and Kapoor, 1973; all cited in Liberato et al., 2004) showed that $P$. xanthii was able to infect papaya. Other studies reported spontaneous infections of papaya by the same species in Taiwan and Korea (Tsay et al., 2011; Joa et al., 2013). This fungus is a widespread colonizer of papaya in different geographic regions of the world, especially as samples identified earlier as $P$. caricae-papayae also represent P. xanthii (Braun et al., 2017).

The samples of the morphological type 2 formed a clade with powdery mildew fungi identified as E. malvae, E. heraclei and E. betae. Samples of morphological type 2 differed from E. malvae by the longer conidia, and the conidiophores of E. malvae arise mostly from towards the ends of mother cells (Braun and Cook, 2012), which was not observed in our samples. However, our samples were morphologically indistinguish- 


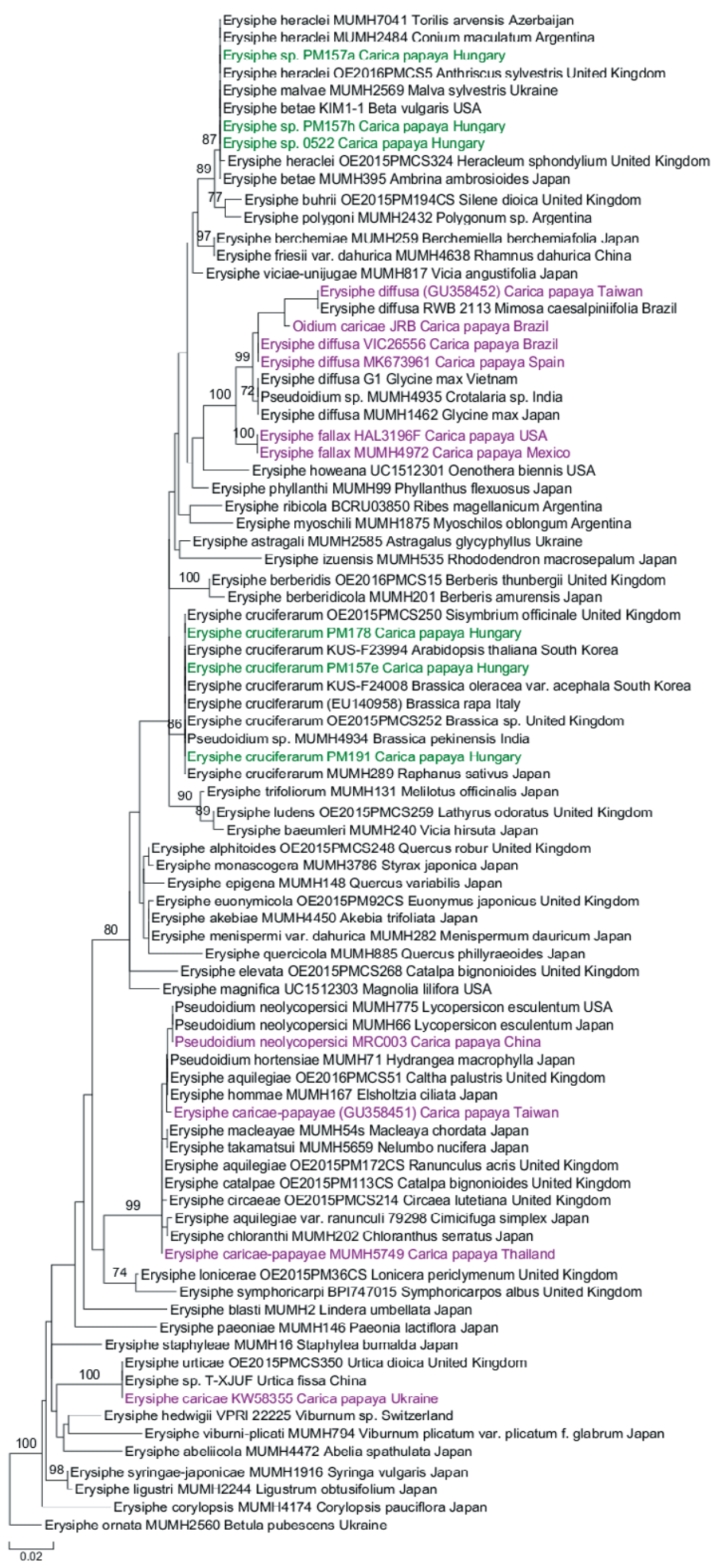

Figure 3. Phylogenetic tree with the greatest likelihood value resulting from the maximum likelihood (ML) analysis of ITS sequences of selected powdery mildew species belonging to the Microsphaera lineage of Erysiphe. Species names are followed by herbarium accession numbers (or GenBank accession numbers in parentheses if the herbarium accession number is not available), name of host plant, and country of collection. Samples collected in the present study are in green font, while other powdery mildew samples from papaya are in purple. Bootstrap values were calculated from 1000 replicates in the ML analysis (values below 70\% and in subclades are not shown). Bar indicates 0.02 expected changes per site per branch. 


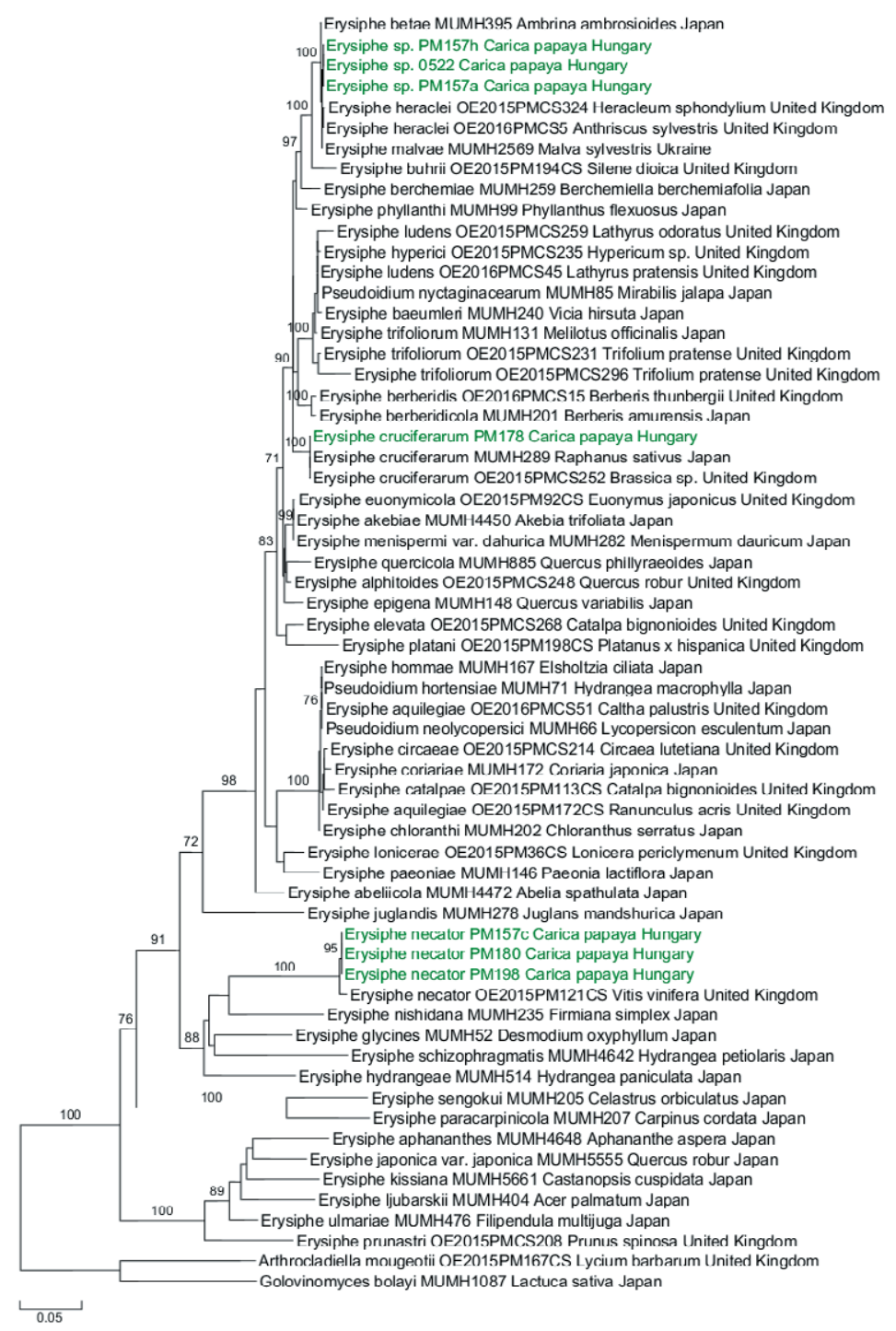

Figure 4. Phylogenetic tree with the greatest likelihood value resulting from the maximum likelihood (ML) analysis of ITS and $m c m 7$ sequences of selected powdery mildew species belonging to the Microsphaera lineage of Erysiphe. Species names are followed by herbarium accession numbers (or GenBank accession numbers in parentheses if the herbarium accession number is not available), name of host plant, and country of collection. Samples collected in the present study are in green font. Bootstrap values were calculated from 1000 replicates in ML analysis (values below $70 \%$ and in subclades are not shown). Bar indicates 0.05 expected changes per site per branch.

able from $E$. betae and E. heraclei. ITS sequences from morphological type 2 belonged to an unresolved complex within the Microsphaera lineage (Takamatsu et al., 2015), so this fungus cannot be unambiguously identified to the species level based solely on ITS sequence data. This could be due to the low phylogenetic resolution of nrDNA sequences at the species level for powdery mildew fungi (Takamatsu et al., 2015; Shin et al., 2019). In order to further characterize, and possibly identify, the fungus in this complex, we also determined the sequence of a fragment of Mcm7. This locus is known to provide greater resolution than ITS among powdery mildew fungi (Ellingham et al., 2019). This sequence is known to differ between $E$. heraclei and $E$. betae, based on the few sequences obtained to date (Ellingham et al., 2019; Shirouzu et al., 2020). Using Mcm7 did not give species-level identification of the fungus with morphological type 2, as our sequences differed from both $E$. heraclei and E. betae. This indicates that a unique haplotype of an unindentified (or unknown) species infected papaya. Sequencing of additional reference samples could confirm if it belongs to an unknown spe- 


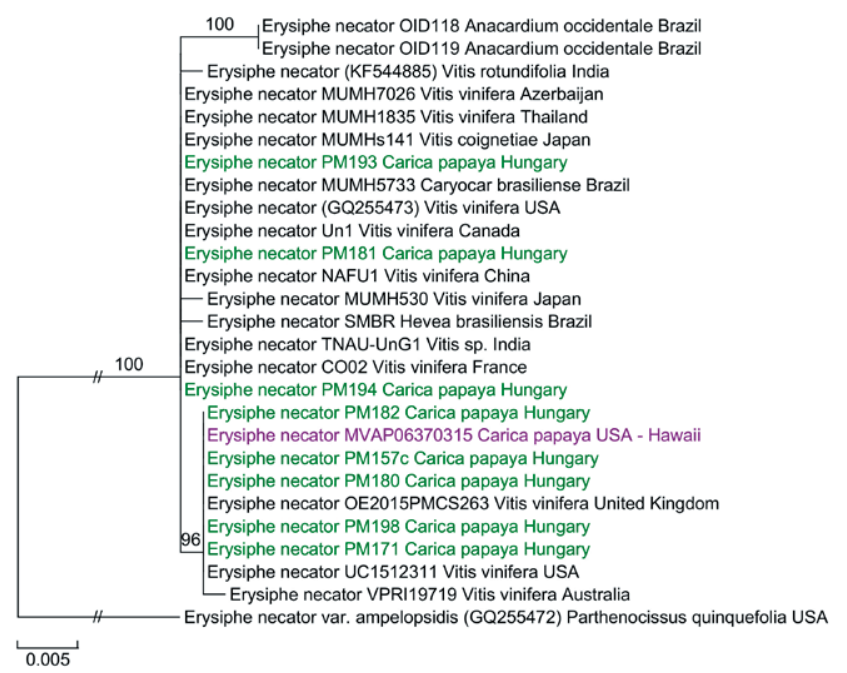

Figure 5. Phylogenetic tree with the greatest likelihood value resulting from the maximum likelihood (ML) analysis of ITS sequences of selected Erysiphe necator samples. Species names are followed by herbarium accession numbers (or GenBank accession numbers in parentheses if herbarium accession number is not available), name of host plant, and country of collection. Samples collected in the present study are in green font, while other powdery mildew samples from papaya are in purple. Bootstrap values were calculated from 1000 replicates in ML analysis (values below 70\% and in subclades are not shown). Bar indicates 0.005 expected changes per site per branch.

cies. We are not aware of any previous study presenting powdery mildew fungi belonging to this species complex from papaya or any other host plants in the Caricaceae. Our results further indicate that fungi from this lineage infect diverse hosts from different plant families.

The assembly containing morphological type 3 samples can be identified as E. cruciferarum. Although this species is found mainly on brassicaceous plants (Braun and Cook, 2012), infectivity of E. cruciferarum on papaya is also known from previous results, as the powdery mildew infecting Brassica napus was able to cause disease on papaya plants (Boesewinkel 1982a, cited in Braun et al., 2007). A checklist of South African powdery mildew fungi also listed papaya as a host of E. cruciferarum (Gorter, 1993). Our sequence results provide further evidence of E. cruciferarum occurring on papaya. It should be noted that E. cruciferarum was detected on papaya leaves collected in the two sampled locations in Hungary, which are more than $100 \mathrm{~km}$ apart.

Erysiphe caricae, the first Erysiphe species on papaya of which the teleomorph has been detected (Bolay, 2005; Braun et al., 2017) is phylogenetically distant from other Erysiphe species occurring on papaya (Braun et al., 2017; and see Figure 3). Moreover, as additional sequences were included in our analysis, this showed that E. caricae formed a group with two powdery mildew samples from Urtica sp., having identical ITS sequences. Further research is required to decipher the relation of E. caricae and the fungi causing powdery mildew on Urtica sp.
Erysiphe necator is mainly associated with plants in the Vitaceae (Braun and Cook, 2012). However, it has been shown recently that this fungus can also infect cashew and rubber tree (Fonseca et al., 2019; Pieroni et al., 2020). Erysiphe necator was also identified from papaya in a single sample from Hawaii (Braun et al., 2017). In the present study, infections of papaya were found to be caused by E. necator in half of the samples. The fungus was found in two distinct locations in Hungary, and the ITS sequences of samples from the two locations were different, indicating at least two independent occurrences of the fungus on papaya. The two groups differed by a fixed nucleotide difference (T/C at the nucleotide position corresponding to no. 48 of the reference sequence GQ255473), which is known to differ between two genetically differentiated $E$. necator subpopulations (Brewer and Milgroom, 2010). Our results suggest that E. necator can readily infect papaya in some circumstances.

Cross inoculations with E. necator and $P$. xanthii from papaya onto healthy papaya plants were unsuccessful. On the other hand, P. xanthii from papaya infected cucumber, and $E$. necator from papaya infected in vitro grapevine leaves. One explanation could be that the powdery mildew growth on papaya is often sparse, providing insufficient inoculum pressure on the healthy plants for successful infections. The respective hosts may also be more susceptible to the corresponding powdery mildew species than papaya. Furthermore, it is also pos- 
sible that the growth conditions in our experiments were less conducive to powdery mildew infections on papaya than on the other host plants.

Erysiphe species detected in the present study are different from the species commonly occurring on papaya (see Braun et al., 2017). This could be that most of the reports have originated from locations where papaya is widely grown, or commonly found. In Hungary, papaya is present in homes of hobby growers or in greenhouses. Papaya is not native in Europe, but the powdery mildew species detected on papaya are established in Hungary (Sz. Nagy and Kiss, 2006). Fungal pathogens (Thines, 2019), including powdery mildews (Limkaisang et al., 2006; Vági et al., 2006; Cook et al., 2015; Beenken, 2017) have been reported to infect introduced non-local plants. This is considered as host range expansion (Thines, 2019), which is similar to the results from the present study of powdery mildew on papaya.

Our findings and the previous reports show that papaya is a host of several different powdery mildew fungi wherever it is grown. This may indicate that papaya could become a host for locally occurring powdery mildew species when this host is out of its native geographic range. This could lead to repeated occurrences of papaya powdery mildew, as papaya is more widely grown around as a crop or as an ornamental.

\section{ACKNOWLEDGEMENTS}

The authors thank Tamás Farkas for providing papaya plants, and for his assistance in sample transport. This research was partly supported by the Széchenyi 2020 Programme, the European Regional Development Fund and the Hungarian Government (GINOP-2.3.2-15-2016-00061), and by the ELTE Institutional Excellence Program by the National Research, Development and Innovation Office (NKFIH-11578/2019-DT).

\section{LITERATURE CITED}

Alcorn J.L., 1968. Cucurbit powdery mildew on pawpaw. Queensland Journal of Agricultural and Animal Sciences 2: 161-164.

Altschul S.F., Gish W., Miller W., Myers E.W., Lipman D.J., 1990. Basic local alignment search tool. Journal of Molecular Biology 215: 403-410.

Aziz A., Poinssot B., Daire X., Adrian M., Bézier A., ... Pugin A., 2003. Laminarin elicits defense responses in grapevine and induces protection against Botry- tis cinerea and Plasmopara viticola. Molecular PlantMicrobe Interactions 16: 1118-1128. https://doi. org/10.1094/MPMI.2003.16.12.1118

Beenken L., 2017. First records of the powdery mildews Erysiphe platani and E. alphitoides on Ailanthus altissima reveal host jumps independent of host phylogeny. Mycological Progress 16: 135-143. https://doi. org/10.1007/s11557-016-1260-2

Boesewinkel H., 1982a. The identity of Oidium caricae and the first recording on papaya, mountain papaya and babaco in New Zealand. Fruits 37: 473-504.

Boesewinkel H., 1982b. Babaco, mountain papaya and papaya: all are susceptible to powdery mildew. New Zealand Journal of Agriculture 45: 28.

Bolay A., 2005. Les Oïdiums de Suisse (Erysiphacées). Cryptogamica Helvetica 20: 1-173.

Braun U., Cook R.T.A., 2012. Taxonomic Manual of the Erysiphales (Powdery Mildews). CBS-KNAW Fungal Biodiversity Centre, Utrecht, The Netherlands.

Braun U., Meeboon J., Takamatsu S., Blomquist C., Fernandez Pavia S., ... Macedo D.M. 2017. Powdery mildew species on papaya - a story of confusion and hidden diversity. Mycosphere 8: 1403-1423. https:// doi.org/10.5943/mycosphere/8/9/7

Brewer M.T., Milgroom M.G., 2010. Phylogeography and population structure of the grape powdery mildew fungus, Erysiphe necator, from diverse Vitis species. BMC Evolutionary Biology 10: 268. https://doi. org/10.1186/1471-2148-10-268

Carvalho F.A., e-Monograph of Caricaceae. Version 1, November 2013 http://herbaria.plants.ox.ac.uk/bol/ Caricaceae, Accessed 19 May 2020

Carvalho F.A., Filer D., Renner S.S., 2015. Taxonomy in the electronic age and an e-monograph of the papaya family (Caricaceae) as an example. Cladistics 31: 321329. https://doi.org/10.1111/cla.12095

Cook R.T.A., Denton J.O., Denton G., 2015. Pathology of oak-wisteria powdery mildew. Fungal Biology 119: 657-671. https://doi.org/10.1016/j.funbio.2015.02.008

Cunningham B., Nelson S., 2012. Powdery mildew of papaya in Hawai'i. Colleague of Tropical Agriculture and Human Resources, University of Hawaii at Mānoa, Plant Disease PD 90: 1-4.

Ellingham O., David J., Culham A., 2019. Enhancing identification accuracy for powdery mildews using previously underexploited DNA loci. Mycologia 111: 798-812. https://doi.org/10.1080/00275514.2019.164 3644

Fan C., Cui H., Ding Z., Gao P., Luan F., 2019. First report of powdery mildew caused by Podosphaera xanthii on okra in China. Plant Disease 103: 10271027. https://doi.org/10.1094/PDIS-09-18-1543-PDN 
Fonseca W., Cardoso J., Ootani M., Brasil S., Assunção F., ... Martins M.V.V., 2019. Morphological, molecular phylogenetic and pathogenic analyses of Erysiphe spp. causing powdery mildew on cashew plants in Brazil. Plant Pathology 68: 1157-1164. https://doi. org/10.1111/ppa.13032

Gorter G., 1993. A revised list of South African Erysiphaceae (powdery mildews) and their host plants. South African Journal of Botany 59: 566-566.

Honoré M.N., Belmonte-Ureña L.J., Navarro-Velasco A., Camacho-Ferre F., 2020. Effects of the size of papaya (Carica papaya L.) seedling with early determination of sex on the yield and the quality in a greenhouse cultivation in continental Europe. Scientia Horticulturae 265: 109218. https://doi.org/10.1016/j.scienta.2020.109218

Joa J., Chung B., Han K., Cho S., Shin H.-D., 2013. First report of powdery mildew caused by Podosphaera xanthii on papaya in Korea. Plant Disease 97: 15141514. https://doi.org/10.1094/PDIS-06-13-0581-PDN

Katoh K., Standley D.M., 2013. MAFFT multiple sequence alignment software version 7: improvements in performance and usability. Molecular Biology and Evolution 30: 772-780. https://doi.org/10.1093/molbev/mst010

Kiss L., Cook R.T.A., Saenz G.S., Cunnington J.H., Takamatsu S., ... Rossman A.Y., 2001. Identification of two powdery mildew fungi, Oidium neolycopersici sp. nov. and $O$. lycopersici, infecting tomato in different parts of the world. Mycological Research 105: 684-697. https://doi.org/10.1017/S0953756201004105

Liberato J.R., Barreto R.W., Louro R.P., 2004. Streptopodium caricae sp. nov., with a discussion of powdery mildews on papaya, and emended descriptions of the genus Streptopodium and Oidium caricae. Mycological Research 108: 1185-1194. https://doi.org/10.1017/ s0953756204000991

Limkaisang S., Cunnington J.H., Wui L.K., Salleh B., Sato Y., ... Takamatsu S., 2006. Molecular phylogenetic analyses reveal a close relationship between powdery mildew fungi on some tropical trees and Erysiphe alphitoides, an oak powdery mildew. Mycoscience 47: 327-335. https://doi.org/10.1007/s10267-006-0311-y

Miller P.A., 1938. Cucurbit powdery mildew on Carica papaya. Phytopathology 28: 672.

Mukhtar I., van Peer A., 2018. Occurrence of powdery mildew caused by Pseudoidium neolycopersici on papaya (Carica papaya) in China. Plant Disease 102: 2645-2645. https://doi.org/10.1094/PDIS-10-171642-PDN

Munjal R.L., Kapoor J.N., 1973. Carica papaya: a new host of Sphaerotheca fuliginea. Indian Phytopathology 26: 366-367.
Murashige T., Skoog F., 1962. A revised medium for rapid growth and bio assays with tobacco tissue cultures. Physiologia Plantarum 15: 473-497.

Nayak A.K., Babu B.K., 2019. First report of powdery mildew caused by Podosphaera fusca on Euphorbia hirta in Odisha state, India. Journal of Plant Pathology 101: 191-191. https://doi.org/10.1007/s42161018-0143-6

Nemes K., Salánki K., Pintye A., 2019. Punica granatum (pomegranate) as new host of Erysiphe platani and Podosphaera xanthii. Phytopathologia Mediterranea 58: 707-711. https://doi.org/10.14601/Phyto-10890

Nomura Y., Takamatsu S., Fujioka K., 2003. Teleomorph of Erysiphe necator var. necator on Vitis vinifera and Ampelopsis brevipedunculata var. heterophylla (Vitaceae) newly found in Japan. Mycoscience 44: 157-158. https://doi.org/10.1007/s10267-003-0094-3

Pérez-García A., Romero D., Fernández-Ortuño D., López-ruiz F., De Vicente A., Tores J.A., 2009. The powdery mildew fungus Podosphaera fusca (synonym Podosphaera xanthii), a constant threat to cucurbits. Molecular Plant Pathology 10: 153-160. https://doi. org/10.1111/j.1364-3703.2008.00527.x

Pieroni L.P., Gorayeb E.S., Benso L.A., Kurokawa S.Y.S., Siqueira O.A.P.A., ... Furtado E.L., 2020. First report of Erysiphe necator causing powdery mildew to rubber tree (Hevea brasiliensis) in Brazil. Plant Disease 104: 3078. https://doi.org/10.1094/PDIS-04-20-0848PDN

Pintye A., Németh M.Z., Molnár O., Horváth Á.N., Spitzmüller Z., ... Kovács G.M., 2020. Improved DNA extraction and quantitative real-time PCR for genotyping Erysiphe necator and detecting the DMI fungicide resistance marker A495T, using single ascocarps. Phytopathologia Mediterranea 59: 97-106. https://doi. org/10.14601/Phyto-11098

Rawal R.D., 2010. Fungal diseases of papaya and their management. Acta Horticulturae 851: 443-446. 10.17660/ActaHortic.2010.851.68

Scholler M., Schmidt A., Siahaan S.A.S., Takamatsu S., Braun U., 2016. A taxonomic and phylogenetic study of the Golovinomyces biocellatus complex (Erysiphales, Ascomycota) using asexual state morphology and rDNA sequence data. Mycological Progress 15: 56. https://doi.org/10.1007/s11557-016-1197-5

Sequeira M., 1992. Notes on Erysiphaceae. Powdery mildew on Carica papaya. Garcia de Orta. Série de Estudos Agronómicos 18: 23-26.

Shin H.-D., La Y.-J., 1993. Morphology of edge lines of chained immature conidia on conidiophores in powdery mildew fungi and their taxonomic significance. Mycotaxon 46: 445-451. 
Shin H.-D., Meeboon J., Takamatsu S., Adhikari M.K., Braun U., 2019. Phylogeny and taxonomy of Pseudoidium pedaliacearum. Mycological Progress 18: 237246. https://doi.org/10.1007/s11557-018-1429-y

Shirouzu T., Takamatsu S., Hashimoto A., Meeboon J., Ohkuma M., 2020. Phylogenetic overview of Erysiphaceae based on nrDNA and MCM7 sequences. Mycoscience 61: 249-258. https://doi.org/10.1016/j. myc.2020.03.006

Silvestro D., Michalak I., 2012. raxmlGUI: a graphical frontend for RAxML. Organisms Diversity \& Evolution 12: 335-337. https://doi.org/10.1007/s13127-011-0056-0

Staden R., Beal K.F., Bonfield J.K., 2000. The Staden package, 1998. Methods in Molecular Biology 132: 115130. https://doi.org/10.1385/1-59259-192-2:115

Stamatakis A., 2014. RAxML version 8: a tool for phylogenetic analysis and post-analysis of large phylogenies. Bioinformatics 30: 1312-1313. https://doi. org/10.1093/bioinformatics/btu033

Stöver B.C., Müller K.F., 2010. TreeGraph 2: Combining and visualizing evidence from different phylogenetic analyses. BMC Bioinformatics 11: 7. https://doi. org/10.1186/1471-2105-11-7

Sz. Nagy G., Kiss L., 2006. A check-list of powdery mildew fungi of Hungary. Acta Phytopathologica et Entomologica Hungarica 41: 79-91.

Takamatsu S., Kano Y., 2001. PCR primers useful for nucleotide sequencing of rDNA of the powdery mildew fungi. Mycoscience 42: 135-139. https://doi. org/10.1007/BF02463987

Takamatsu S., Ito H., Shiroya Y., Kiss L., Heluta V., 2015. First comprehensive phylogenetic analysis of the genus Erysiphe (Erysiphales, Erysiphaceae) I. The Microsphaera lineage. Mycologia 107: 475-489. https://doi.org/10.3852/15-007

Takamatsu S., Siahaan S.A.S., Moreno-Rico O., Cabrera de Álvarez M.G., Braun U., 2016. Early evolution of endoparasitic group in powdery mildews: molecular phylogeny suggests missing link between Phyllactinia and Leveillula. Mycologia 108: 837-850. https://doi. org/10.3852/16-010

Thines M., 2019. An evolutionary framework for host shifts - jumping ships for survival. New Phytologist 224: 605-617. https://doi.org/10.1111/nph.16092

Tsay J.-G., Chen R.-S., Wang H.-L., Wang W.-L., Weng B.-C., 2011. First report of powdery mildew caused by Erysiphe diffusa, Oidium neolycopersici, and Podosphaera xanthii on papaya in Taiwan. Plant Disease 95: 1188-1188. https://doi.org/10.1094/PDIS-0511-0362

Vági P., Kovács G.M., Kiss L., 2006. Host range expansion in a powdery mildew fungus (Golovinomyces sp.) infecting Arabidopsis thaliana: Torenia fournieri as a new host. European Journal of Plant Pathology 117: 89-93. https://doi.org/10.1007/s10658-006-9072-x

van der Bijl P.A., 1921. On a fungus - Ovulariopsis papayae, n. sp. - which causes powdery mildew on the leaves of the pawpaw plant (Carica papaya, Linn.). Transactions of the Royal Society of South Africa 9: 187-189. 10.1080/00359192109520208

Ventura J.A., Costa H., da Silva Tatagiba J., 2004. Papaya diseases and integrated control. In: Diseases of Fruits and Vegetables: Volume II (S. A. M. H. Naqvi ed.), Kluwer Academic Publishers, Dordrecht, The Netherlands, 201-268.

Vielba-Fernández A., de Vicente A., Pérez-García A., Fernández-Ortuño D., 2019. First report of powdery mildew elicited by Erysiphe diffusa on papaya (Carica papaya) in Spain. Plant Disease 103: 2477. https://doi. org/10.1094/PDIS-03-19-0627-PDN

Yen J., Wang C., 1973. Étude sur les champignons parasites du Sud-Est asiatique XXII: Les Oidium de Formose (II). Revue de Mycologie 37: 125-153. 